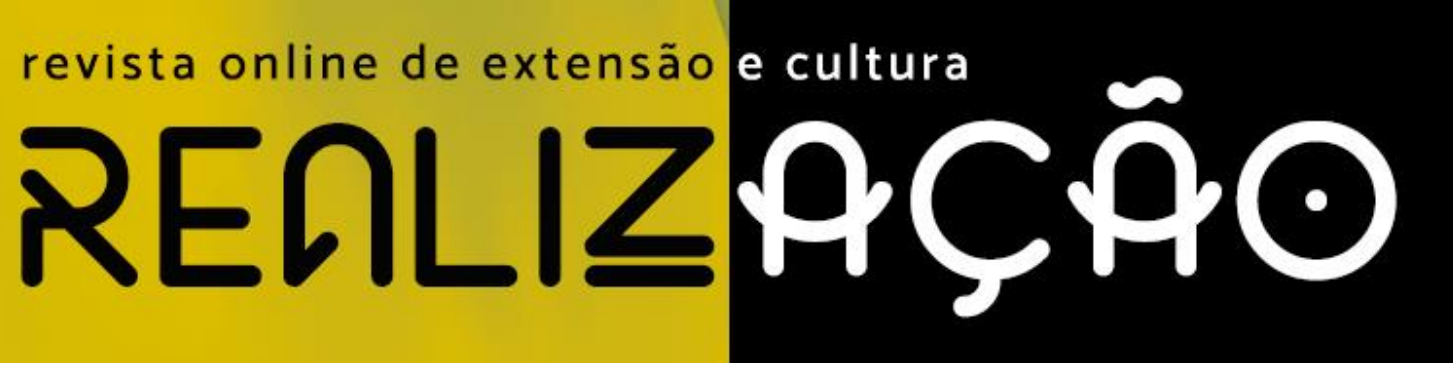

DOI 10.30612/realizacao.v8i16.15381

\title{
ATLETA ANIMAL: PARTICIPAÇÃO DE ANIMAIS EM PRÁTICAS ESPORTIVAS SOBRE A PERSPECTIVA DA COMUNIDADE DAS CIÊNCIAS AGRÁRIAS
}

\author{
ANIMAL ATHLETE: ANIMAL PARTICIPATION IN SPORTS PRACTICES ON A \\ PERSPECTIVE OF THE AGRICULTURAL SCIENCES COMMUNITY
}

\author{
Guilherme Resende de Almeida ${ }^{1}$ \\ Jean Kaique Valentim ${ }^{2}$ \\ Alexander Alexandre de Almeida ${ }^{3}$ \\ Tatiana Marques Bittencourt ${ }^{1}$ \\ Joyce Zanella
}

RESUMO: As Vaquejadas, Rodeios e Provas de Laço são modalidades esportivas e culturais de nosso País que estão entremeadas no cotidiano de muitos brasileiros há muitas gerações. Busca-se, com o presente trabalho, analisar a opinião de profissionais e estudantes das ciências agrárias de todo o país sobre tais práticas. Foi realizada uma pesquisa descritiva - exploratória via questionário, disponibilizada na internet a partir do Google Docs formulários - a partir da qual foram obtidos 250 registros. O cenário atual da atividade exibe diversos pontos que ainda são muito discutidos e polemizados. Na análise dos resultados, a maioria dos entrevistados está na faixa etária de 15 a 25 anos; são homens e mulheres com ensino superior completo, conhecedores dos preceitos de bem-estar, que concordam com o uso de animais na prática de esportes e conhecem a legislação que regulamenta essas práticas. Observa-se que 39,6\% deste público concorda parcialmente com a utilização de animais nesta prática de esportes, outros $35,2 \%$ concordam totalmente e $13,9 \%$ discorda do uso de animais para fins esportivos. Quanto à fiscalização, $84 \%$ dos entrevistados acham que o Brasil não fiscaliza esse segmento, necessitando de maiores cuidados. Quando perguntado aos participantes sobre o que seria necessário para que os animais tenham seus direitos garantidos, 41,2\% relataram conscientização por parte da população, $29,6 \%$ fiscalização do governo e $25,5 \%$ proibição de qualquer prática que possa prejudicar os animais. Conclui-se com este trabalho que a população das ciências agrárias concorda parcialmente com a utilização de animais em práticas esportivas,

\footnotetext{
1 Universidade Federal do Mato Grosso

2 Universidade Federal da Grande Dourados

${ }^{3}$ Universidade Federal dos Vales do Jequitinhonha e Mucuri
}

2021 | Volume 08 | No 16 ISSN: 2358-3401 
revista online de extensão e cultura

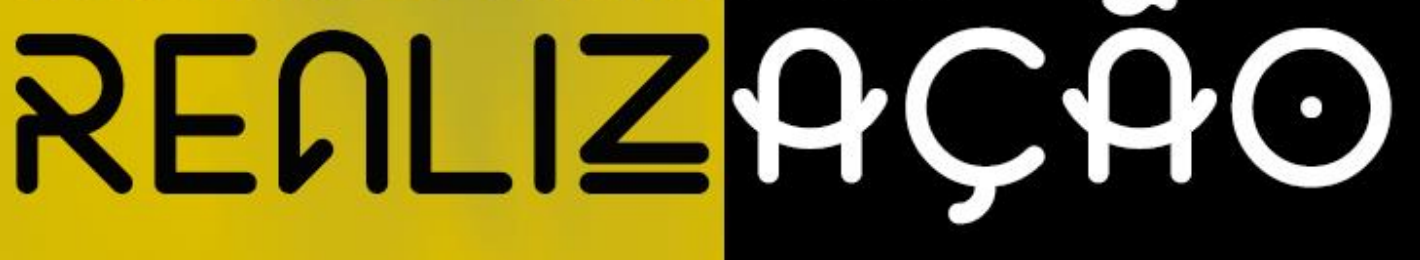

\begin{tabular}{lcc}
\hline Menos de 15 & 1 & 0,4 \\
15 a 25 & 134 & 53,6 \\
25 a 35 & 92 & 36,8 \\
35 a 50 & 16 & 6,4 \\
Acima de 50 & 4 & 1,6 \\
Não informou & 3 & 1,2 \\
\hline \multicolumn{1}{c}{ Escolaridade } & $\mathbf{N}$ & $\%$ \\
\hline Ensino fundamental completo & 2 & 0,8 \\
Ensino fundamental incompleto & 1 & 0,4 \\
Ensino médio completo & 41 & 16,4 \\
Ensino médio incompleto & 4 & 1,6 \\
Ensino superior incompleto & 76 & 30,4 \\
Ensino superior completo & 57 & 22,8 \\
Pós graduação & 66 & 26,4 \\
Prefere não informar & 3 & 1,2 \\
\hline
\end{tabular}

N: número de participantes; $\%$ porcentagem

Entrando na vertente do presente estudo, o Gráfico 1 demonstra a opinião dos entrevistados sobre o verdadeiro conceito de Bem-estar animal, mostrando que (161) 64,4\% dos envolvidos afirmam conhecer as definições de Bem-estar e sua aplicação no meio rural, (70) $28 \%$ conhece parcialmente o conceito de bem-estar, $16(6,4 \%)$ relatam o desconhecimento sobre a definiçãa do bem-estar e $3(1,2 \%)$ preferiram não comentar sobre o assunto.

Gráfico 1. Conceito de bem-estar animal

2021 | Volume 08 | No 16 ISSN: $2358-3401$

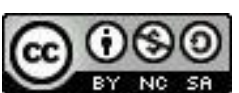

Esta obra está licenciada com uma Licença Creative Commons Atribuição-NãoComercial-CompartilhaIgual 3.0 

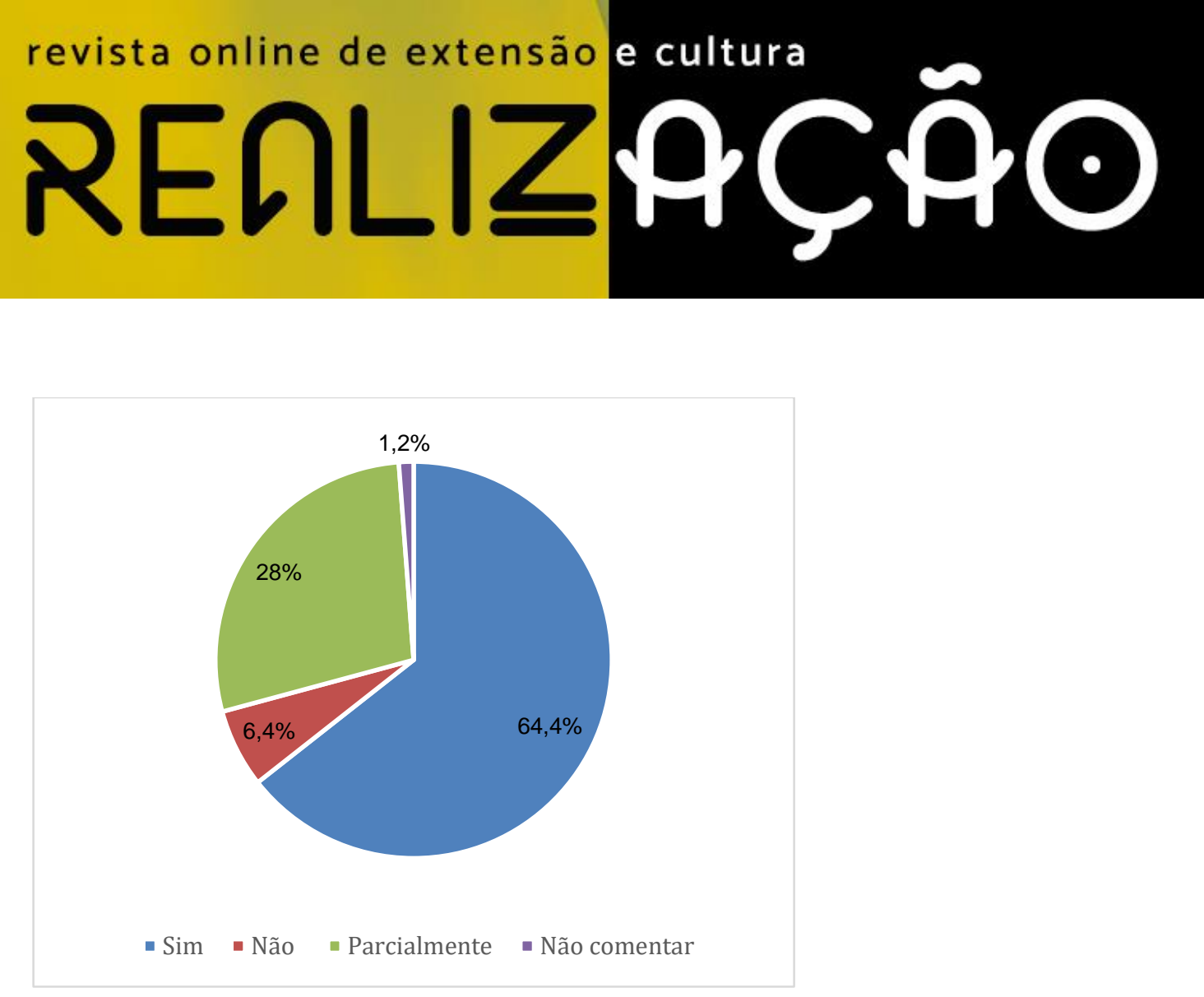

O bem-estar animal está relacionado com diversas questões e conceitos diferentes, onde o objetivo principal é garantir uma melhor qualidade de vida ao animal, onde ele possa ser capaz de se manter equilibrado fisiologicamente e emocionalmente, já que eles são animais sencientes, e desta forma, capazes de sentirem dores, medos, aflições, angustias.

As perguntas do questionário foram destinadas a acadêmicos e profissionais dos cursos de ciências agrarias, por esse motivo já era de se esperar que os mesmos tivessem conhecimento sobre a definição e empregabilidade do bem-estar animal.

No gráfico 2 tem-se as opiniões sobre a utilização de animais para práticas esportivas e quais dos esportes tende a afetar mais o bem-estar dos animais, observa-se, que $39,6 \%$ deste público concorda parcialmente com a utilização de animais nesta prática de esportes, outros $35,2 \%$ concordam totalmente com essa prática e 13,9\% discorda do uso de animais para fins esportivos.

Gráfico 2. Uso de animais em práticas esportivas 

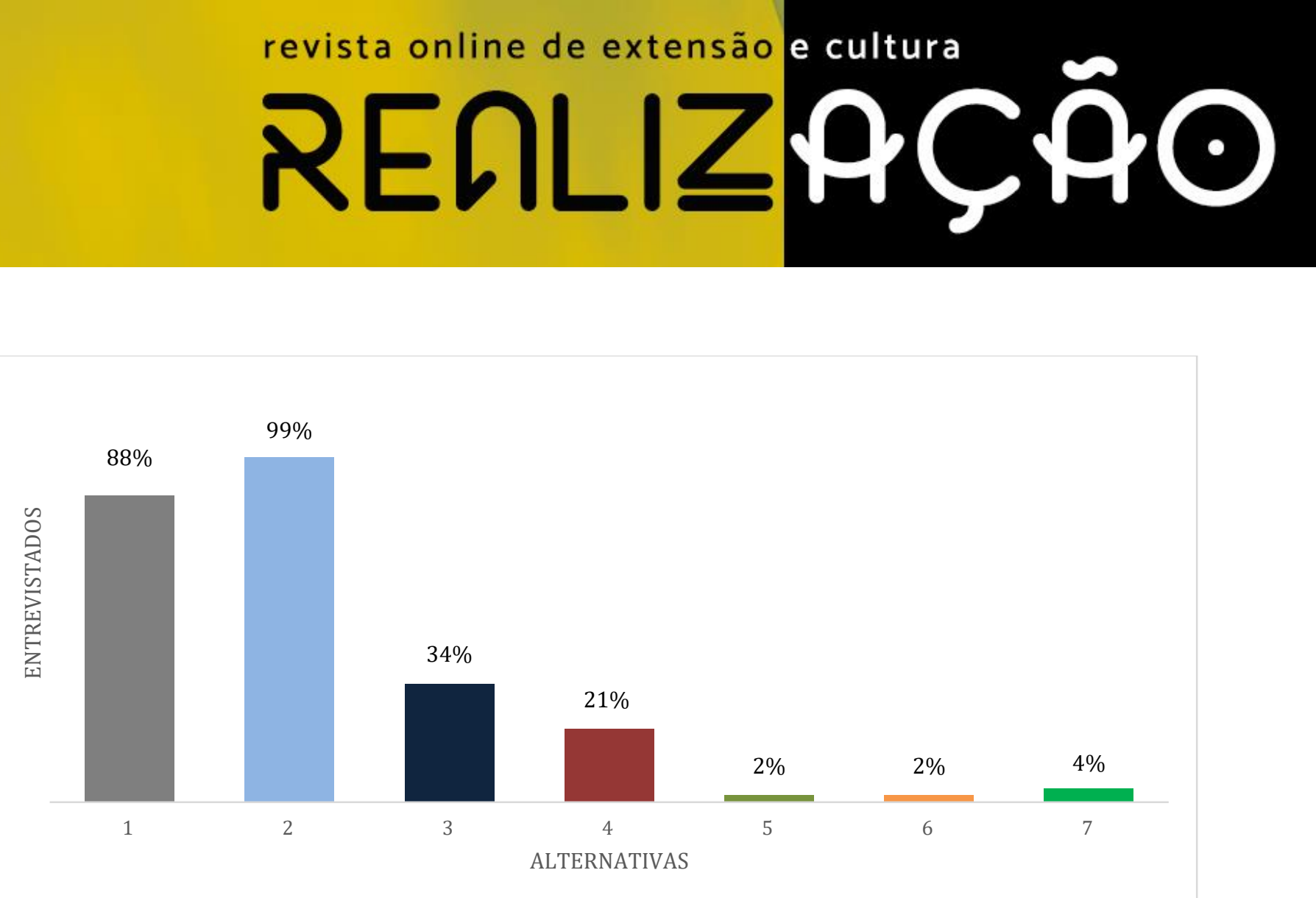

1.concorda; 2. Concorda parcialmente; 3. Discorda; 4. Discorda parcialmente; 5. Depende da prática;

6. Não conhece; 7. Prefere não comentar

Quanto ao assunto sobre os tipos de modalidades existentes e seus efeitos no bemestar dos animais, notou-se na tabela 2 que 32,8\% dos entrevistados acham que a vaquejada é a atividade que mais fere os direitos dos animais. Tais resultados corroboram com Simon et al. (2018) onde 67,3\% dos entrevistados acreditam que os animais sofrem quando participam de rodeios e atividades similares.

Tabela 2. Tipos de modalidades existentes e seus efeitos no bem-estar dos animais

Quais mais afetas os

Atividades esportivas

animais?

\begin{tabular}{cccccc}
\hline Vaquejadas & Rodeios & $\begin{array}{c}\text { Provas de } \\
\text { laço }\end{array}$ & $\begin{array}{c}\text { Provas } \\
\text { equestres }\end{array}$ & $\begin{array}{c}\text { Todas as } \\
\text { atividades }\end{array}$ & Outras \\
\hline 82 & 56 & 39 & 5 & 27 & 41 \\
32,8 & 22,4 & 15,6 & 2 & 10,8 & 16,4
\end{tabular}

$\mathrm{N}$ : número de entrevistados; \% porcentagem

2021 | Volume 08 | No 16 ISSN: $2358-3401$ 


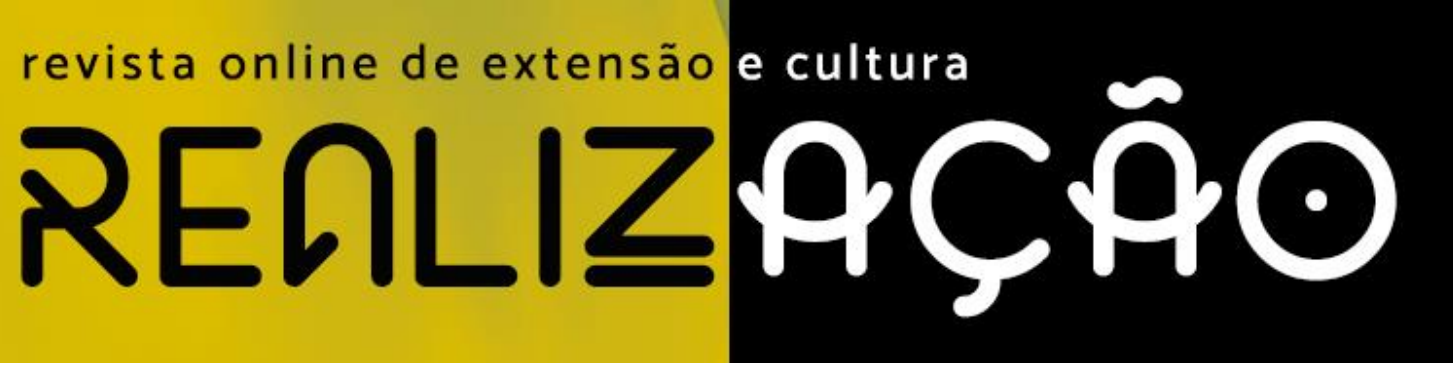

Quando indagado sobre a legislação que eleva tais práticas a manifestação cultural percebe-se na Tabela 3 que 54,4\% dos entrevistados diz que a conhece, e 39,2\% destes não concordam com esta lei. Outro ponto importante elucidado na presente pesquisa foi a opinião deste público alvo com relação a fiscalização dos órgãos governamentais nestas atividades esportivas, onde $84 \%$ dos questionados relataram que o país não apresenta uma legislação firma para o regimento das atividades

Tabela 3. Legislação que eleva tais práticas a manifestação cultural.

\begin{tabular}{|c|c|c|c|c|c|}
\hline Variáveis & & Sim & Não & $\begin{array}{c}\text { Prefere não } \\
\text { falar }\end{array}$ & Outros \\
\hline \multicolumn{6}{|l|}{ Você conhece a lei 13.364 que eleva } \\
\hline $\begin{array}{l}\text { o rodeio, a vaquejada, bem como as } \\
\text { demais práticas relacionadas à }\end{array}$ & $\mathrm{N}$ & 136 & 109 & 5 & $*$ \\
\hline $\begin{array}{l}\text { condição de manifestação cultural } \\
\text { nacional? }\end{array}$ & $\%$ & 54,4 & 43,6 & 2 & \\
\hline \multirow{2}{*}{ Se sim, você concorda com esta lei? } & $\mathrm{N}$ & 94 & 98 & 58 & $*$ \\
\hline & $\%$ & 37,6 & 39,2 & 23,2 & \\
\hline $\begin{array}{l}\text { Você acha que o nosso País é bem } \\
\text { estruturado no quesito de }\end{array}$ & $\mathrm{N}$ & 28 & 210 & 8 & 4 \\
\hline $\begin{array}{l}\text { fiscalização do uso de animais nestas } \\
\text { modalidades? }\end{array}$ & $\%$ & 11,2 & 84 & 3,2 & 1,6 \\
\hline
\end{tabular}

N: número de entrevistados; \% porcentagem; * Não apresentava a opção

De acordo com Amorim et al. (2007) 78\% das pessoas questionadas sobre a legislação de proteção animal dizem desconhecer a mesma. Muito tem se falado sobre as legislações que regem os direitos dos animais, por este motivo faz se indispensável estudos

\section{1 | Volume 08 | No 16 ISSN: $2358-3401$}


